\title{
The role of selected adipokines in tumorigenesis and metabolic disorders in patients with adrenal tumors
}

\author{
Anna Babinska, Piotr Kmieć, Krzysztof Sworczak
}

Department of Endocrinology and Internal Medicine, Medical University of Gdansk, Gdansk, Poland

Submitted: 30 April 2019; Accepted: 12 August 2019

Online publication: 4 March 2020

Arch Med Sci 2023; 19 (2): 467-477

DOI: https://doi.org/10.5114/aoms.2020.93486

Copyright $\odot 2020$ Termedia \& Banach

\begin{abstract}
Recently, more and more attention has been directed to the role of adipose tissue and adipocytokines in the pathogenesis of metabolic and inflammatory disorders in humans. Excess fat tissue has also been associated with a higher risk of malignancies. Advances in the research on the role of adipokines in adrenal tumors may elucidate the relationship between various types of adipose tissue (visceral, subcutaneous, and periadrenal) and metabolic disorders observed in hormonally active adrenal tumors, as well as associations with adrenal cortex cancer. In patients with active or cured Cushing syndrome, increased leptin and resistin concentrations as well as release of pro-inflammatory cytokines can be associated with cardiovascular risk. Also, the renin-angiotensin-aldosterone system in patients with primary hyperaldosteronism may affect the metabolic activity of the adipose tissue. Elevated resistin concentrations in this group of patients are associated with morphological changes of the myocardium independently of the effects of the metabolic syndrome. Further, it has been suggested that hypoadiponectinemia comprises an additional factor in the pathogenesis of carbohydrate metabolism disorders and the risk of cardiovascular complications in pheochromocytoma patients. Understanding the mechanisms of action of adipokines may be important in developing prophylactic and therapeutic strategies in hormonally active and malignant tumors of the adrenal glands.
\end{abstract}

Key words: adipokines, adipokine receptors, subclinical Cushing syndrome, Cushing syndrome, pheochromocytoma, primary hyperaldosteronism, adrenocortical carcinoma.

\section{Introduction}

Obesity is a major social problem. The number of obese people in the United States in 2010 was 78 million [1]. Obesity increases the risk of hypertension (HT), dyslipidemia, type 2 diabetes (DM2), coronary artery disease (CAD), stroke, gallbladder disease, osteoarthritis, and sleep apnea. Also, the relationship between obesity and many human cancers has been proven: in all malignancies, obesity was associated with an increased mortality rate - by $52 \%$ in men and $88 \%$ in women [1-3].

Apart from its role in the storage of lipids, the adipose tissue (AT) is considered the largest endocrine gland in humans. It regulates energy homeostasis, metabolism, inflammatory processes, immunity, hormonal equilibrium, and bone turnover [4-7]. Concerning metabolic homeo-

\author{
Corresponding author: \\ Anna Babinska MD \\ Department of Endocrinology \\ and Internal Medicine \\ Medical University of Gdansk \\ 7 Dębinki St \\ 80-288 Gdansk, Poland \\ Phone: +48583492840 \\ Fax: +48 583492841 \\ E-mail: a.mail@wp.pl
}


stasis, physiologically, hormones secreted by the AT (adipokines) signal functional status to other organs. In this respect, the crucial peptides are leptin and adiponectin. What is more, substances produced by the fat tissue are also involved in immunity and inflammation. Obesity and adipocyte dysfunction induce production of inflammatory cytokines (commonly, and also here, referred to as adipocytokines together with adipokines), the secretory profile of the AT becomes pathologic. Adipocytokines likely contribute to metabolic diseases and inflammation [8, 9].

Adipose tissue is considered to be involved in the pathology of rheumatoid arthritis (RA), systemic lupus erythematosus, and Behçet's disease [10]. In active arthritis peri-articular fat and synovial tissue were shown to release leptin, resistin and adiponectin, and the secretion of proinflammatory adipokines was increased [10]. Excessive expression of adipokines was also demonstrated in the intestinal mesenteric fat tissue in patients with Crohn's disease. Research on the effect of adipokines on acute pancreatitis is ongoing: it seems that serum concentrations of resistin and leptin are elevated in this disease and may constitute its marker [11]. Kumar et al. [12] described increased adipogenesis and increased expression of adiponectin and leptin in the orbital tissue of patients with active thyroid orbitopathy.

Chronic inflammation that takes place in the adipose tissue may affect the development of metabolic disorders related to obesity. In many studies, a relationship has been demonstrated between adipocytokine secretion observed in obesity and the development of insulin resistance, DM2, hypertension $(\mathrm{HT})$, non-alcoholic steatohepatitis, and adverse lipid profile $[8,9]$.

Furthermore, a relationship has been investigated between various adipocytokines and human neoplasms, including benign and malignant tumors of the endocrine system. The main mechanisms underlying the association between obesity and the risk of malignancy include:

- insulin resistance and the insulin-like growth factor 1 (IGF1) system (insulin inhibits apoptosis and stimulates IGF1 synthesis, which is a growth factor and promotes cancer; in obesity IGF1-binding protein synthesis in the liver is reduced, as a result, IGF-1 bioavailability increases),

- impact of adiposity on the biosynthesis and bioavailability of endogenous sex hormones,

- obesity-induced low-grade chronic systemic inflammation,

- alterations in the levels of adipocyte-derived factors $[3,5,13,14]$.

In many human cancers (mainly those related to obesity) the role of leptin, which promotes carcinogenesis, as well as adiponectin, has been investigated. In humans, leptin has been shown to increase the growth of tumor cells associated with obesity, but it has also been proven to affect cancers not associated with obesity, for example, central nervous system tumors - gliomas and meningiomas [15].

Adiponectin, on the other hand, has a protective effect and anti-proliferative properties. Decreased adiponectin concentration has been demonstrated in cancers of the stomach, prostate, endometrium and breast [5].

There are a few reports concerning the role of adipose tissue in endocrine diseases. In this review the role of adipokines in oncogenesis and metabolic disorders in the course of human adrenal gland tumors is discussed.

\section{Methods}

This review was based on an electronic search of literature using the PubMed database. Associations between adipokine and cytokine levels and the risk of cancers and metabolic disorders in adrenal tumors were investigated.

\section{Characterization of selected adipokines}

\section{Adiponectin}

The best known adipokine is adiponectin $[4,5]$. Adiponectin is believed to be a mediator of obesity-related cancers and exerts direct anticancer effects via its receptors $[5,16]$. Adiponectin is mainly synthesized in the white adipose tissue; secretion in the brown adipose tissue is low [7, 17]. Researchers also noted the presence of adiponectin in other animal tissues: skeletal muscles [18], liver [19], colon [20], cardiac tissue [21], salivary glands [22], bone marrow [23], fetal tissue and placenta [24], as well as cerebrospinal fluid [25], and breast milk [26]. Its expression in various tissues may indicate its para- and autocrine action $[4,5]$. Adiponectin is a 247-amino acid monomer protein that circulates in the form of trimers, low molecular weight hexamers (LMW), or multimeric form with high molecular weight (HMW). Various spatial forms have different physiological properties, and the HMW and trimeric forms have the highest biological activity $[4,5]$. It seems that the key factor in exerted biological effects of adiponectin is not its total concentration but the ratio of the HMW fraction to total adiponectin $[4,5]$.

The effects of adiponectin are mediated via its receptors, which are present in various organs and tissues. Yamauchi was first to isolate adiponectin receptors in human and mouse tissues in 2003 [27]. To date, three adiponectin receptors have been identified: two main, i.e. AdipoR1 and AdipoR2, and one receptor similar to that in the cadherin family $[5,28]$. Receptor expression cor- 
relates with insulin concentration, and decreases in diabetic mice [29]. Obesity seems to reduce the expression of AdipoR1/AdipoR2, thus reducing the sensitivity to adiponectin, which in turn leads to a vicious cycle of insulin resistance [30]. Aging and long-term consumption of high-fat foods were reported to reduce the concentration of adiponectin and increase the expression of its receptors [31].

Adiponectin, through its receptors, activates several intracellular signaling pathways, mainly AMPK, but also mammalian target of rapamycin (mToR), nuclear factor $\kappa \mathrm{B}(\mathrm{NF}-\kappa \mathrm{B})$, c-Jun N-terminal kinase (JNK), and signal transducer and activator of transcription proteins, STATs [32, 33].

The negative correlations between circulating adiponectin and obesity (especially central), insulin resistance and DM2 are well known [34]. A meta-analysis of prospective studies involving a total of 14,598 participants and 2,623 DM2 cases showed that higher adiponectin concentration was associated with a lower risk of DM2 [34]. Higher adiponectin levels were also associated with a moderate reduction of coronary artery disease risk in men with DM [35]. In addition, hypoadiponectinemia was associated with an adverse atherosclerotic lipid profile [36]; the risk of cardiovascular complications was inversely proportional to adiponectin concentrations [37].

Adiponectin has insulin-sensitizing action and reports by some authors indicate that hypoadiponectinemia is associated not only with insulin resistance, DM, and CAD [38-40], but also with malignant tumors [6]. The anti-inflammatory effect of adiponectin is primarily conveyed by inhibition of T-cell activation and proliferation, and blocking of tumor necrosis factor $\alpha$ (TNF- $\alpha)$ release. Adiponectin also inhibits the synthesis of interferon $\gamma$ (IFN- $\gamma$ ), a molecule that stimulates cytotoxicity of natural killer (NK) cells. Adiponectin induces the synthesis of interleukin (IL)-10, an anti-inflammatory molecule, and receptor antagonist for IL-1. It also increases monocyte apoptosis and phagocytosis by macrophages, and inhibits the expression of TNF- $\alpha$-induced adhesion molecules [25].

The protective effect of adiponectin in cancer is based on its anti-proliferative properties. It inhibits angiogenesis and intracellular signaling associated with carcinogenesis [41]. Adiponectin reduces the proliferation of tumor and endothelial cells in the breast and prostate by binding mitogenic growth factors [41]. Several cancer cell lines express receptors for adiponectin, suggesting its possible direct effects on these cells. Expression of adiponectin receptors has been demonstrated in breast, prostate, liver, stomach, colorectal, pancreatic, and lung carcinoma $[5,16$, 42-45].
Chou et al. analyzed the relationship between AdipoR1 and AdipoR2 expression in various human neoplasms and cancer progression assessed as presence of local lymphatic and distant metastases. A statistically significant relationship was found between AdipoR1 expression and kidney cancer with and without metastasis. In the course of kidney cancer, a neoplasm strongly associated with obesity, lower serum adiponectin levels and significantly higher expression of AdipoR1 receptors in tumor tissue are found than in non-obesity-associated neoplasms [16]. In breast cancer, high expression of AdipoR1 was associated with vascular invasion. In contrast, in gastric cancer, high AdipoR1 expression was associated with longer survival [16].

\section{Leptin}

Leptin is the second well-known human adipokine. It is mainly produced by differentiated adipocytes, and its effects are contrary to those of adiponectin [46]. Leptin suppresses appetite and induces energy expenditure, although in the obese elevated leptin levels are present presumably due to resistance to the hormone [8].

Leptin is a pro-inflammatory adipokine. It enhances the formation of free oxygen radicals and induces proliferation of endothelial cells and expression of metalloproteinases within the extracellular matrix. It also activates neutrophils, monocytes and cytotoxic NK cells, stimulates production of proinflammatory cytokines by monocytes and lymphocytes, increases proliferation of T-lymphocytes and monocytes, and promotes angiogenesis. Leptin acts via its receptor, Ob-R (located on the surface of endothelial cells and leukocytes) [4], regulates many intracellular pathways: JAK (Janus kinase), STAT (signal transducer and activator of transcription) protein, PI3K (phosphatidylinositol 3-kinases), AKT (protein kinase B), and MAPK (mitogen-activated protein kinase). In addition, leptin increases proliferation via a variety of growth factors such as vascular endothelial growth factor (VEGF), fibroblast growth factor 21 (FGF21), and IGF-1 [47, 48].

A positive relationship between leptin concentration and coronary artery calcification was demonstrated in 860 healthy adults, who had neither diabetes nor established cardiovascular risk factors [49]. Leptin induced C-reactive protein (CRP) secretion, which is a well-known marker of cardiovascular risk [49].

Leptin is one of the most potent adipokines in metabolic regulation. It regulates body weight by signaling the state of nutrition to other organs in particular to the hypothalamus, which produces neuropeptides and neurotransmitters that affect energy delivery and expenditure. Leptin also plays 
an important role in the regulation of homeostasis. It improves insulin sensitivity in the liver and skeletal muscles and regulates the function of pancreatic $\beta$ cells. Interactions between leptin and inflammation are bi-directional: proinflammatory cytokines increase the synthesis and release of leptin, which in turn contributes to chronic inflammation in obesity [8].

Leptin was shown to increase the growth of breast, esophageal, stomach, pancreatic, prostate, ovarian, and lung cancer cells [50-52]. A relationship between leptin concentration and colon cancer cell proliferation was also suggested [53]. Further, it was indicated that leptin promotes the proliferation of some breast tumors in vitro as well as tumor invasiveness and angiogenesis in some animal models $[53,54]$. The oncogenic effects of leptin have not been elucidated yet. It is believed this protein activates intracellular signal transduction pathways [55]. In addition to receptor effects of leptin, e.g. in gastric cancer, its direct paracrine and autocrine action not mediated by its receptor was proposed [51]. It seems that oncogenic effects of leptin are exhibited more prominently in obesity-related cancers (esophageal, breast, stomach, colon and pancreatic) compared to those in which obesity plays a smaller role [56]. In epidemiological studies, an association between serum leptin concentrations and tumor progression was suggested. The strongest relationship was demonstrated for colon, prostate and breast cancers [57-59].

The effect of leptin on endocrine tumors is very poorly understood. Ob-R presence was demonstrated in the human adrenal glands [60]. Associations between leptin levels and adrenocortical and adrenal medullary neoplasms have not been investigated yet.

\section{Resistin}

Resistin was first discovered as an obesity hormone in animal studies. In obesity, an increase in serum resistin concentration was observed [61]. In experimental studies, resistin was demonstrated to act antagonistically to insulin $[62,63]$. It seems that in humans resistin acts on insulin signaling pathway, causing dephosphorylation of 3-phosphorylated phosphoinositide [64]. Recent research in humans also indicates its role in the pathogenesis of atherosclerosis. Its concentration was demonstrated to be independently associated with an increased risk of myocardial infarction and ischemic stroke in a large cohort of middle-aged subjects and in the Women's Health Initiative Observation Study [65]. Also, high resistin concentration was associated with morphological changes in the heart independently of the presence of metabolic syndrome [66].
Recent reports indicate that high serum resistin levels are an important risk factor for heart failure in the elderly, independently of CRP, insulin resistance or obesity $[67,68]$.

Resistin is mainly produced by monocytes and macrophages (which isstimulated byTNF $\alpha$ and IL-6), and its synthesis is induced during adipogenesis [69-71]. In turn, resistin activates the NF- $\kappa B$ pathway and, as a result, induces TNF- $\alpha$, IL- 6 , and IL-12 production. Resistin stimulates expression of adhesion molecules: vascular cell adhesion molecule 1 (VCAM-1) and intercellular adhesion molecule 1 (ICAM-1) in endothelial cells, and induces endothelin 1, a strong spasmogen.

Epidemiological studies in humans showed a relationship between elevated resistin concentration and higher risk of DM2, myocardial infarction, and atherosclerosis. It seems that resistin concentration may serve as a marker of metabolic diseases in humans [8].

\section{Other proinflammatory cytokines secreted by the adipose tissue}

Associations between a pathologic adipocytokine profile (reduced adiponectin and increased leptin as well as resistin levels) and the development of insulin resistance, DM, and the risk of cardiovascular diseases have been reported by many researchers $[4,72,73]$. In studies of the pathologies of cardiovascular and metabolic diseases as well as malignancies cytokines secreted by the AT other than the three adipokines above have also been investigated.

Pro-inflammatory cytokines, including IL-6, TNF- $\alpha$, and monocyte chemoattractant protein 1 (MCP-1), are involved in many pathological processes including inflammation, endothelial damage, atherosclerosis, insulin resistance, HT, and bone remodeling $[4,74]$.

Interleukin 6 is a cytokine that plays an important role in the development of insulin resistance in obesity. Adipose tissue contributes to $10-35 \%$ of circulating IL- 6 in humans. Hyperglycemia causes an increase in IL- 6 concentration. Expression of IL-6 in the adipose tissue correlates positively with insulin resistance both in vivo and in vitro [8]. In a cohort of 1293 healthy elderly subjects followed prospectively for a mean of 11.6 years, elevated IL-6 levels were associated with a doubling of cardiovascular risk and all-cause mortality [36]. Also, elevated IL-6 concentrations were shown to constitute a risk factor of DM2 and myocardial infarction [34, 37].

Tumor necrosis factor $\alpha$ is part of the inflammatory system, capable of initiating a cytokine cascade including synergistic and inhibitory reactions that control the synthesis and expression of other proinflammatory cytokines [8]. 
TNF- $\alpha$ promotes the expression of adhesive molecules in endothelial cells and synthesis of endothelin 1 and angiotensinogen, which contributes to HT. Pro-inflammatory effects aside, TNF- $\alpha$ and IL-6 lower adiponectin secretion [23, 27, 39].

\section{Adipocytokines in benign human adrenal cortex tumors}

Wide use of thoracic and abdominal imaging studies results in an increased prevalence of adrenal tumors, which amounts to $10 \%$ among the elderly [75]. Most of the discovered tumors are hormonally inactive; rarely they have subclinical or overt hormonal activity [75]. All hormonally active tumors may lead to many metabolic disorders and an increased risk of cardiovascular diseases [76-80]. There are also reports indicating increased risk of these diseases in non-functional adrenal incidentaloma patients (NFAI) [81].

Adipokines were shown to be secreted by the periadrenal fat tissue surrounding adrenal tumors and their receptors to be present in tumor tissues $[16,82,83]$. Researchers' interest has been directed at a potential effect of adipokines on hormonal activity and metabolic disorders in hormonally active adrenal tumors.

\section{Adrenal Cushing's and subclinical Cushing's syndrome}

Endogenous Cushing's syndrome (CS) is a consequence of chronically increased serum glucocorticoid concentrations. Authors of many studies have shown that glucocorticoid overproduction in both overt and subclinical Cushing's syndrome (CS and SCS) increases the risk of metabolic diseases and cardiovascular events [72, 74, 81, 84-87]. In patients with CS, the mortality rate due to complications of metabolic diseases increases fourfold compared with the healthy population $[72,88]$.

In a number of studies a relationship has been shown between concentrations of cortisol and adipocytokines [72]. Wagenmakers et al. showed that an adverse adipokine profile (i.e. low adiponectin and high leptin and resistin levels) persisted even after CS patients had been cured [89]. Persisting central distribution of the AT negatively affects the adipocytokine profile and likely contributes to sustained increased cardiovascular risk, independently of active hypercortisolemia [89]. The authors of the current review observed higher TNF- $\alpha$ and IL- 6 concentrations as well as lower adiponectin levels in 20 SCS patients compared to healthy volunteers [90].

Dogruk Unal et al. demonstrated that low adiponectin concentration is a valuable determinant of SCS in patients with accidentally discovered adrenal tumors [87]. Barahona et al. recorded lower concentrations of adiponectin in clinically active
CS female patients as well as those treated for CS (over the preceding $11 \pm 6$ years) compared to healthy volunteers, although this difference was not significant when age was taken into account [91].

Concerning another adipokine, resistin, in a study by Krsek et al. [92], its concentration was higher in 10 female CS patients compared to healthy volunteers. Resistin levels positively correlated with body mass index (BMI). Resistin level reduction did not reach statistical significance 9 months after surgical treatment, although the amount of visceral fat decreased among enrolled patients.

Although hyperleptinemia has been repeatedly confirmed in CS patients, a relationship between cortisol and leptin levels is unclear [72, 93]. Gavrila et al. showed that cortisol and leptin circadian profiles are strongly related: their peak concentrations occur during morning hours. Peak leptin concentration followed that of cortisol with a 2-hour time difference, which suggests a relationship between these hormones [94]. Also, in human studies, administration of dexamethasone resulted in an increase in leptin in obese subjects, which was independent of sex, age, and insulin sensitivity [94]. Further, Widjaja et al. recorded a significant reduction in leptin concentration 2.5 years after transsphenoidal surgery for ACTH-dependent Cushing's syndrome. In their small group of patients $(n=9)$, insulin, cortisol concentrations, and $\mathrm{BMI}$ returned to reference values for sex and age [95].

In contrast, Weise and co-authors found that diurnal leptin profile was normal in 18 patients with CS, and observed no correlation between leptin and cortisol levels. This lack of association between both hormones in CS was also underlined by the fact that corticotropin-releasing hormone $(\mathrm{CRH})$ administration before and 10 days after surgical treatment of hypercortisolemia in 12 CS patients did not affect leptin concentration (despite significant differences in cortisol levels, i.e. basally and in response to $\mathrm{CRH}$ both before and after surgery) [96].

A possible explanation for these findings is the fact that so far no studies have investigated the relative amount of specific body fat stores (namely visceral and subcutaneous fat) and leptin concentration in CS patients. This distinction in tissue type is crucial because subcutaneous fat produces two to three times more leptin than visceral fat [97].

Although the pathogenesis of hypoleptinemia in CS patients is unclear, it is thought to be a compensatory mechanism for excess glucocorticoids, due to which food intake is inhibited (via suppression of neuropeptide $Y$ and stimulation of proopiomelanocortin (POMC), which has anorectic effects) $[72,98]$.

Central obesity, a typical feature of CS, is associated with altered secretion of adipocytokines, 
which contributes to metabolic and cardiovascular complications [5, 85, 88]. In CS patients, serum concentrations of leptin and resistin, as well as proinflammatory cytokines such as TNF- $\alpha$ and IL-6, are increased [72]. It is possible that a pathological adipocytokine profile constitutes an additional risk factor of metabolic and cardiovascular diseases in CS patients. The situation is not so clear in patients with SCS, in whom obesity and overweight are less frequent and less severe than in patients with overt CS $[72,86]$. Probably, even small but chronic exposure to excess glucocorticoids in both CS and SCS can lead to central accumulation of adipose tissue, which results in a persistent, unfavorable profile of adipokines and cytokines. Despite reports on the influence of adipocytokines on the risk of metabolic diseases in CS and SCS patients, literature data are often contradictory $[81,99,100]$; therefore, future studies including larger patient populations are required.

\section{Primary hyperaldosteronism}

In primary hyperaldosteronism (PA) patients compared to primary hypertensives the risk of cardiovascular diseases and the frequency of metabolic syndrome are increased [101-104]. Resection of an aldosterone-producing adenoma leads to regression of these disorders. The role of adipocytokines in primary aldosteronism has been poorly studied.

A relationship between hyperaldosteronism and fat tissue function is indicated by reports on the presence of the mineralocorticoid receptor (MR) in the AT, which mediates actions of both aldosterone and glucocorticoids in adipocyte differentiation, adipocytokine secretion, and lipid accumulation [105]. The RAAS may be involved in the modulation of adipocytokines in individuals with excessive serum aldosterone [106, 107].

Letizia et al. showed that mineralocorticoids, such as aldosterone, play an important role in adipose tissue function, regulating differentiation of preadipocytes to mature adipocytes, and inducing inflammatory adipocytokines [108]. In their study, higher secretion of leptin and lower secretion of adiponectin in adrenal fat tissue surrounding aldosterone-producing tumors were observed [108].

Rossi et al. analyzed AdipoR1 and AdipoR2 receptor expression in normal adrenal glands (which were removed during renal cell carcinoma surgery) and aldosterone-secreting adenomas [109]. Significantly higher expression of adiponectin receptors in aldosteronomas compared to normal adrenal cortex was revealed. The authors speculated that adiponectin modulates aldosterone secretion by affecting adiponectin receptor subtypes in the adrenal cortex [109].
In another report, lacobellis et al. compared adipocytokine levels in PA and essential hypertension patients. Higher concentrations of resistin were found in the former group, while leptin levels were higher and adiponectin lower after accounting for the presence of metabolic syndrome in both patient groups [66]. It is possible that high resistin concentrations in PA may be the result of abnormal adipocyte function due to exposure to prolonged high concentrations of aldosterone [66]. However, a direct effect of aldosterone on resistin concentration has not been demonstrated yet [66].

Similarly, lower adiponectin levels in PA patients compared to low renin essential hypertensives were also found by Fallo et al. [110]. Low adiponectin levels may contribute to endothelial dysfunction [66].

On the other hand, Haluzík et al. found that leptin concentrations were not different between PA and matched healthy controls at baseline; however, a significant increase in leptin levels was observed in PA patients after treatment (both surgical and pharmacological) [111]. The same observation concerning pre- and post-surgery leptin levels for PA was made by Torpy et al., who suggested that improved insulin secretion due to correction of hypokalemia may be the underlying reason for increase in leptinemia [112].

The few studies, in which only selected adipokines in PA patients were investigated, and in light of the presence of adipocyte receptors in the tissue of adenomas secreting aldosterone, indicate the need for further studies on larger groups of patients to explain the influence of the fat tissue on metabolic disorders observed in this group of patients.

\section{Adrenocortical carcinoma}

Research on the relationship between the adipose tissue and human neoplasms is largely observational, and there are limited data on rare malignancies, including those of the adrenal glands.

Chou et al. investigated expression of adiponectin receptors in various, including non-obesity-associated human neoplasms, and were the first to show their presence in adrenocortical cancer (ACC) [16]. The authors showed that AdipoR1 expression was much higher in obesity-associated neoplasms compared to those in which the influence of obesity as an etiological factor was not proven [16].

The authors of the current review evaluated differences in the expression of adiponectin receptors in benign and malignant adrenal tumors by immunohistochemistry. In an analysis of 128 resected adrenal tumors both AdipoR1 and AdipoR2 expression levels were significantly higher in ACC compared to benign adrenal hyperplasia and adrenocortical adenomas [82]. It seems that 
higher adipokine receptor expression in malignant adrenal tumors can be explained by down-regulation, which is present in epithelial breast cancer as well as Barrett's adenocarcinoma $[113,114]$. It can be assumed that low serum adiponectin levels are associated with tumorigenic effects, resulting in increased expression of AdipoR1 and R2 receptors in adrenal tumor tissue [82, 83].

An attempt to evaluate the proliferative effect of leptin in adrenal tumors was undertaken by Glasow et al. in 1999 [60]. The researchers examined normal and neoplastic adrenocortical tissue and found that leptin does not regulate the proliferation of adrenocortical tumors despite the presence of its receptor in the tumors [60].

In the above-mentioned study conducted by the authors of this review (resected adrenal tumors from 128 patients), it was demonstrated that leptin receptor expression was absent or minimal in half of examined benign tumors (nodular hyperplasia and adrenocortical adenomas), while being much higher in ACCs $[82,83]$. We also sought for a relationship between the expression of adipokine and leptin receptors in ACC tissue and the progression of this rare human tumor [83], but none was demonstrated. Effective radical surgical treatment remains the established prognostic factor [115].

Considering the role of adipokines in neoplasia and the presence of adipokine receptors in adrenal tumors, it can be hypothesized that adipokines play a role also in human adrenocortical cancers, which are non-obesity-associated neoplasms.

\section{Pheochromocytoma}

Pheochromocytoma (PHEO) is a neoplasm that arises from chromaffin cells of the neural tube of the sympathetic and parasympathetic nervous system. It comprises approximately $1-8.7 \%$ of incidentally discovered adrenal tumors according to various reports [116-118]. PHEOs produce one or more catecholamine (epinephrine, norepinephrine, dopamine, which are metabolized to metanephrines, normetanephrines, and 3-methoxytramine, respectively), as well as other active substances, all of which lead to various clinical symptoms [116-118].

Obesity is rare in patients with PHEO due to the catabolic effect of excessive catecholamine secretion, which stimulates lipolysis $[75,119,120]$. However, adrenal glands are embedded in fat tissue, which has been shown to secrete adipokines that can affect PHEO [108]. There are reports assessing the influence of the adipose tissue on PHEO tumor metabolism that suggest its effect on metabolic disorders in this group of patients [119, 120].

Glucose metabolism disorders including DM are a relatively common feature in patients with
PHEO. According to the literature, impaired glucose tolerance was observed in $25 \%$ to $75 \%$ of patients with PHEO and about 33\% developed DM $[116,119,120]$. Supraphysiological catecholamine concentrations reduce insulin secretion and are the main cause of DM in PHEO patients. Wiesner et al. reported that glucose intolerance in PHEOs is caused by increased insulin resistance [121]. Possibly, insulin resistance is another factor in the development of DM in pheochromocytoma patients.

In some studies, lower adiponectin concentrations compared to controls were observed in PHEO patients $[119,122]$. Elenkova et al. suggested that hypoadiponectinemia was the missing link in the pathogenesis of carbohydrate metabolism disorders in these patients, and that it may be an additional risk factor for cardiovascular and metabolic complications [119].

Epinephrine up-regulates the expression of adiponectin receptors. It seems that high catecholamine concentrations present in PHEO, i.e. the cause of glucose intolerance and DM, induce compensatory expression of adiponectin receptors, particularly AdipoR1, in PHEO tumor tissue, probably due to decreased serum adiponectin concentration [122].

In the available literature, Isobe et al. speculated that, contrary to epinephrine, high levels of norepinephrine induce adiponectin secretion. It was suggested that this mechanism is protective against occurrence of DM in PHEO patients with excess norepinephrine secretion [122].

The authors of the current review investigated adipokine and leptin receptor expression in tumor tissues of 40 adrenal PHEO patients. AdipoR1 and R2 receptor expression was significantly higher in PHEO compared to both benign and malignant adrenocortical tumors [82]. Also, leptin receptor expression in PHEO tumors was higher than in adrenocortical tumors [82].

In studies by other authors, serum leptin concentrations in patients with PHEO tumors were evaluated [122]. It was shown that chronic overproduction of catecholamines that occurs in PHEO did not suppress leptin secretion in these patients. This may be related to the development of tolerance to a chronic excess of catecholamines in the adipose tissue [123].

The interplay between fat tissue surrounding PHEO and possible stimulation of leptin secretion by catecholamines may be associated with higher expression of Ob-R in this type of tumor. In fact, in our previous studies, expression of leptin receptor was significantly higher in PHEO compared to ACC. Higher expression of adiponectin and leptin receptors in $\mathrm{PHEO}$ may result from a significantly stronger effect of catecholamines on adipokine secretion by the AT in comparison to the effect of adrenocortical hormones [82]. 
Presence of adipokine receptors in PHEO tumors in humans as well as the relationship between low adiponectin concentration and increased risk of DM and insulin resistance in PHEO patients indicates the role of adipose tissue in metabolic disorders in this pathology.

\section{Conclusions}

The role of adipocytokines in hormonally active adrenal tumors and their possible effect on metabolic disorders and cardiovascular risk has been investigated scarcely. Elucidating the interplay between excess hormone levels and adipocytokines remains a challenge for future studies.

Presence of adipokine receptors in adrenal cortex and medulla tumors, and, particularly, their high expression in malignant tumors, suggest the possible effect of adipokines on neoplasia in these non-obesity-related neoplasms. Understanding the mechanisms linking adiponectin and leptin with proliferation may be important in the development of anticancer prophylaxis and therapy not only in obesity-associated malignancies. The pathophysiological significance of adipokine receptors and their potential prognostic value in assessment of the risk of cancer incidence, recurrence and treatment results in obesity-related cancers warrant the necessity of future studies. It is possible that treatment with adiponectin receptor analogues or clinical use of adiponectin may have direct beneficial effects in many human cancers. However, currently, lifestyle modifications remain the most important factor in the prevention of cancer and metabolic disorders related to obesity.

\section{Conflict of interest}

The authors declare no conflict of interest.

\section{References}

1. Executive summary: Guidelines (2013) for the management of overweight and obesity in adults: a report of the American College of Cardiology/American Heart Association Task Force on Practice Guidelines and the Obesity Society published by the Obesity Society and American College of Cardiology/American Heart Association Task Force on Practice Guidelines. Based on a systematic review from the The Obesity Expert Panel, 2013. Obesity (Silver Spring) 2014; 22 Suppl 2: S5-39.

2. Calle EE, Rodriguez C, Walker-Thurmond K, Thun MJ. Overweight, obesity, and mortality from cancer in a prospectively studied cohort of U.S. adults. N Engl J Med 2003; 348: 1625-38.

3. Park J, Euhus DM, Scherer PE. Paracrine and endocrine effects of adipose tissue on cancer development and progression. Endocr Rev 2011; 32: 550-70.

4. Siemińska L. Adipose tissue. Pathophysiology, distribution, sex differences and the role in inflammation and cancerogenesis. Endocrinol Pol 2007; 58: 330-42.
5. Dalamaga M, Diakopoulos KN, Mantzoros CS. The role of adiponectin in cancer: a review of current evidence. Endocr Rev 2012; 33: 547-94.

6. Kelesidis I, Kelesidis T, Mantzoros CS. Adiponectin and cancer: a systematic review. Br J Cancer 2006; 94: 1221-5.

7. Ziemke F, Mantzoros CS. Adiponectin in insulin resistance: lessons from translational research. Am J Clin Nutr 2010; 91: 258S-61S.

8. Jung UJ, Choi MS. Obesity and its metabolic complications: the role of adipokines and the relationship between obesity, inflammation, insulin resistance, dyslipidemia and nonalcoholic fatty liver disease. Int J Mol Sci 2014; 15: 6184-223.

9. Cao H. Adipocytokines in obesity and metabolic disease. J Endocrinol 2014; 220: T47-59.

10. Schäffler A, Müller-Ladner U, Schölmerich J, Büchler C. Role of adipose tissue as an inflammatory organ in human diseases. Endocr Rev 2006; 27: 449-67.

11. Schäffler A, Landfried K, Völk M, et al. Potential of adipocytokines in predicting peripancreatic necrosis and severity in acute pancreatitis: pilot study. J Gastroenterol Hepatol 2007; 22: 326-34.

12. Kumar S, Coenen MJ, Scherer PE, Bahn RS. Evidence for enhanced adipogenesis in the orbits of patients with Graves' ophthalmopathy. J Clin Endocrinol Metab 2004; 89: 930-5.

13. van Kruijsdijk RC, van der Wall E, Visseren FL. Obesity and cancer: the role of dysfunctional adipose tissue. Cancer Epidemiol Biomarkers Prev 2009; 18: 2569-78.

14. Gallagher EJ, LeRoith D. Minireview: IGF, insulin, and cancer. Endocrinology 2011; 152: 2546-51.

15. Sergentanis TN, Tsivgoulis G, Perlepe C, et al. Obesity and risk for brain/CNS tumors, gliomas and meningiomas: a meta-analysis. PLoS One 2015; 10: e0136974.

16. Chou SH, Tseleni-Balafouta S, Moon HS, et al. Adiponectin receptor expression in human malignant tissues. Horm Canc 2010; 1: 136-45

17. Maeda K, Okubo K, Shimomura I, et al. cDNA cloning and expression of a novel adipose specific collagen-like factor, apM1 (AdiPose Most abundant Gene transcript 1). Biochem Biophys Res Commun 1996; 221: 286-9.

18. Delaigle AM, Jonas JC, Bauche IB, Cornu O, Brichard SM. Induction of adiponectin in skeletal muscle by inflammatory cytokines: in vivo and in vitro studies. Endocrinology 2004; 145: 5589-97.

19. Kaser S, Moschen A, Cayon A, et al. Adiponectin and its receptors in non-alcoholic steatohepatitis. Gut 2005; 54: 117-21.

20. Fayad R, Pini M, Sennello JA, et al. Adiponectin deficiency protects mice from chemically induced colonic inflammation. Gastroenterology 2007; 132: 601-14.

21. Piñeiro R, Iglesias MJ, Gallego R, et al. Adiponectin is synthesized and secreted by human and murine cardiomyocytes. FEBS Lett 2005; 579: 5163-9.

22. Katsiougiannis S, Kapsogeorgou EK, Manoussakis MN, Skopouli FN. Salivary gland epithelial cells: a new source of the immunoregulatory hormone adiponectin. Arthritis Rheum 2006; 54: 2295-9.

23. Brochu-Gaudreau K, Rehfeldt C, Blouin R, et al. Adiponectin action from head to toe. Endocrine 2010; 37: 11-32.

24. Chen J, Tan B, Karteris E, et al. Secretion of adiponectin by human placenta: differential modulation of adiponectin and its receptors by cytokines. Diabetologia 2006; 49: 1292-302.

25. Schäffler A, Müller-Ladner U, Schölmerich J, Büchler C. Role of adipose tissue as an inflammatory organ in human diseases. Endocr Rev 2006; 27: 449-67. 
26. Bronsky J, Karpísek M, Bronská E, et al. Adiponectin, adipocyte fatty acid binding protein, and epidermal fatty acid binding protein: proteins newly identified in human breast milk. Clin Chem 2006; 52: 1763-70.

27. Yamauchi T, Kamon J, Ito Y, et al. Cloning of adiponectin receptors that mediate antidiabetic metabolic effects. Nature 2003; 423: 762-9.

28. Kadowaki T, Yamauchi T. Adiponectin and adiponectin receptors. Endocr Rev 2005; 26: 439-51.

29. Tsuchida A, Yamauchi T, Ito $Y$, et al. Insulin/Foxo1 pathway regulates expression levels of adiponectin receptors and adiponectin sensitivity. J Biol Chem 2004; 279: 30817-22.

30. Ouchi N, Kihara S, Arita Y, et al. Adiponectin, an adipocyte-derived plasma protein, inhibits endothelial NF-kappaB signaling through a cAMP-dependent pathway. Circulation 2000; 102: 1296-301.

31. Bullen JW Jr, Bluher S, Kelesidis T, Mantzoros CS. Regulation of adiponectin and its receptors in response to development of diet-induced obesity in mice. Am J Physiol Endocrinol Metab 2007; 292: E1079-86.

32. Miyazaki T, Bub JD, Uzuki M, Iwamoto Y. Adiponectin activates c-Jun $\mathrm{NH}$ 2-terminal kinase and inhibits signal transducer and activator of transcription 3. Biochem Biophys Res Commun 2005; 333: 79-87.

33. Bråkenhielm E, Veitonmäki N, Cao R, et al. Adiponectin-induced antiangiogenesis and antitumor activity involve caspase-mediated endothelial cell apoptosis. Proc Natl Acad Sci USA 2004; 101: 2476-81.

34. Li S, Shin HJ, Ding EL, van Dam RM. Adiponectin levels and risk of type 2 diabetes: a systematic review and meta-analysis. JAMA 2009; 302: 179-88.

35. Schulze MB, Shai I, Rimm EB, Li T, Rifai N, Hu FB. Adiponectin and future coronary heart disease events among men with type 2 diabetes. Diabetes 2005; 54: 534-9.

36. Okada T, Saito E, Kuromori Y, et al. Relationship between serum adiponectin level and lipid composition in each lipoprotein fraction in adolescent children. Atherosclerosis 2006; 188: 179-83.

37. Pischon T, Girman CJ, Hotamisligil GS, et al. Plasma adiponectin levels and risk of myocardial infarction in men. JAMA 2004; 291: 1730-7.

38. Hivert MF, Sullivan LM, Fox CS, et al. Associations of adiponectin, resistin, and tumor necrosis factor-alpha with insulin resistance. J Clin Endocrinol Metab 2008; 93: 3165-72.

39. Weyer C, Funahashi T, Tanaka S, et al. Hypoadiponectinemia in obesity and type 2 diabetes: close association with insulin resistance and hyperinsulinemia. J Clin Endocrinol Metab 2001; 86: 1930-5.

40. Hotta K, Funahashi T, Arita Y, et al. Plasma concentrations of a novel, adipose-specific protein, adiponectin, in type 2 diabetic patients. Arterioscler Thromb Vasc Biol 2000; 20: 1595-9.

41. Bub JD, Miyazaki T, Iwamoto Y. Adiponectin as a growth inhibitor in prostate cancer cells. Biochem Biophys Res Commun 2006; 340: 1158-66.

42. Barb D, Williams CJ, Neuwirth AK, Mantzoros CS. Adiponectin in relation to malignancies: a review of existing basic research and clinical evidence. Am J Clin Nutr 2007; 86: s858-66.

43. Mistry T, Digby JE, Chen J, Desai KM, Randeva HS. The regulation of adiponectin receptors in human prostate cancer cell lines. Biochem Biophys Res Commun 2006; 348: 832-8.

44. Petridou ET, Mitsiades N, Gialamas S, et al. Circulating adiponectin levels and expression of adiponectin receptors in relation to lung cancer: two case-control studies. Oncology 2007; 73: 261-9.

45. Dalamaga M, Migdalis I, Fargnoli JL, et al. Pancreatic cancer expresses adiponectin receptors and is associated with hypoleptinemia and hyperadiponectinemia: a case-control study. Cancer Causes Control 2009; 20: 625-33.

46. Cohen B, Novick D, Rubinstein M. Modulation of insulin activities by leptin. Science 1996; 274: 1185-8.

47. Nieman KM, Romero IL, Van Houten B, Lengyel E. Support tumorigenesis and metastasis. Biochim Biophys Acta 2013; 1831: 1533-41.

48. Ray A, Cleary MP. The potential role of leptin in tumor invasion and metastasis. Cytocine Growth Factor Rev 2017; 38: 80-97.

49. Qasim A, Mehta NN, Tadesse MG, et al. Adipokines, insulin resistance, and coronary artery calcification. J Am Coll Cardiol 2008; 52: 231-6.

50. Tilg H, Moschen AR. Adipocytokines: mediators linking adipose tissue, inflammation and immunity. Nat Rev Immunol 2006; 6: 772-83.

51. Wiwanitkit V. Interaction between leptin and leptin receptor in gastric carcinoma: gene ontology analysis. Rev Esp Enferm Di 2007; 99: 201-5.

52. Horiguchi A, Sumitomo M, Asakuma J, et al. Increased serum leptin levels and over expression of leptin receptors are associated with the invasion and progression of renal cell carcinoma. J Urol 2006; 176: 1631-5.

53. Husting SD, Berger NA. Energy balance, host-related factors, and cancer progression. J Clin Oncol 2010; 28: 4058-65.

54. Nkhata KJ, Ray A, Schuster TF, Grossmann ME, Cleary MP. Effects of adiponectin and leptin co-treatment on human breast cancer cell growth. Oncol Rep 2009; 21: 1611-9.

55. Pai R, Lin C, Tran T, Tarnawski A. Leptin activates STAT and ERK2 pathways and induces gastric cancer cell proliferation. Biochem Biophys Res Commun 2005; 331: 984-92.

56. Beales IL, Garcia-Morales C, Ogunwobi OO, Mutungi G. Adiponectin inhibits leptin-induced oncogenic signaling in oesophageal cancer cell by activation of PTP1B. Mol Cell Endocrinol 2014; 382: 150-8.

57. Stattin P, Lukanova A, Biessy C, et al. Obesity and colon cancer: does leptin provide a link? Int J Cancer 2004; 109: 149-52.

58. Chang S, Hursting SD, Contois $\mathrm{JH}$, et al. Leptin and prostate cancer. Prostate 2001; 46: 62-7.

59. Wu MH, Chou YC, Chou WY, et al. Circulating levels of leptin, adiposity and breast cancer risk. Br J Cancer 2009; 100: 578-82.

60. Glasow A, Bornstein SR, Chrousos GP, Brown JW, Scherbaum WA. Detection of Ob-receptor in human adrenal neoplasms and effect of leptin on adrenal cell proliferation. Horm Metab Res 1999; 31: 247-51.

61. Janowska J, Zahorska-Markiewicz B, Olszanecka-Glinianowicz $M$. Relationship between serum resistin concentration and proinflammatory cytokines in obese women with impaired and normal glucose tolerance. Metabolism 2006; 55: 1495-9.

62. Steppan CM, Bailey ST, Bhat S, et al. The hormone resistin links obesity to diabetes. Nature 2001; 409: 307-12.

63. Steppan CM, Lazar MA. Resistin and obesity-associated insulin resistance. Trends Endocrinol Metab 2002; 13: 18-23. 
64. Barnes KM, Miner JL. Role of resistin in insulin sensitivity in rodents and humans. Curr Protein Pept Sci 2009; 10: 96-107.

65. Rajpathak SN, Kaplan RC, Wassertheil-Smoller S, et al. Resistin, but not adiponectin and leptin, is associated with the risk of ischemic stroke among postmenopausal women: results from the Women's Health Initiative. Stroke 2011; 42: 1813-20.

66. Iacobellis G, Petramala L, Cotesta D, et al. Adipokines and cardiometabolic profile in primary hyperaldosteronism. J Clin Endocrinol Metab 2010; 95: 2391-8.

67. Butler J, Kalogeropoulos A, Georgiopoulou V, et al. Serum resistin concentrations and risk of new onset heart failure in older persons: the health, aging, and body composition (Health $\mathrm{ABC}$ ) study. Arterioscler Thromb Vasc Biol 2009; 29: 1144-9.

68. Frankel DS, Vasan RS, D’Agostino RB Sr, et al. Resistin, adiponectin, and risk of heart failure the Framingham offspring study. J Am Coll Cardiol 2009; 53: 754-62.

69. McTernan CL, McTernan PG, Harte AL, Levick PL, Barnett $\mathrm{AH}$, Kumar S. Resistin, central obesity, and type 2 diabetes. Lancet 2002; 359: 46-7.

70. Patel L, Buckels AC, Kinghorn IJ, et al. Resistin is expressed in human macrophages and directly regulat ed by PPAR gamma activators. Biochem Biophys Res Commun 2003; 300: 472-6.

71. Lehrke M, Reilly MP, Millington SC, Iqbal N, Rader DJ, Lazar MA. An inflammatory cascade leading to hyperresistinemia in humans. PLoS Med 2004; 1: e45.

72. Valassi E, Biller BM, Klibanski A, Misra M. Adipokines and cardiovascular risk in Cushing's syndrome. Neuroendocrinology 2012; 95: 187-206.

73. lacobellis G, Petramala L, Cotesta D, et al. Adipokines and cardiometabolic profile in primary hyperaldosteronism. J Clin Endocrinol Metab 2010; 95: 2391-8.

74. Debono M, Bradburn M, Bull M, Harrison B, Ross RJ, Newell-Price J. Cortisol as a marker for increased mortality in patients with incidental adrenocortical adenomas. J Clin Endocrinol Metab 2014; 99: 4462-70.

75. Bednarczuk T, Bolanowski M, Sworczak K, et al. Adrenal incidentaloma in adults - management recommendations by the Polish Society of Endocrinology. Endokrynol Pol 2016; 67: 234-58.

76. Tauchmanova L, Rossi R, Biondi B, et al. Patients with subclinical Cushing's syndrome due to adrenal adenoma have increased cardiovascular risk. J Clin Endocrinol Metab 2002; 87: 4872-8.

77. Swiatkowska-Stodulska R, Sworczak K. Disorders of hemostasis in overt and subclinical hypercortisolism. Exp Clin Endocrinol Diabetes 2013; 121: 588-94.

78. Terzolo M, Pia A, Ali A, et al. Adrenal incidentaloma: a new cause of the metabolic syndrome? J Clin Endocrinol Metab 2002; 87: 998-1003.

79. Tuna MM, Imga NN, Doğan BA, et al. Non-functioning adrenal incidentalomas are associated with higher hypertension prevalence and higher risk of atherosclerosis. J Endocrinol Invest 2014; 37: 765-68.

80. Di Dalmazi G, Vicennati V, Garelli S, et al. Cardiovascular events and mortality in patients with adrenal incidentalomas that are either non-secreting or associated with intermediate phenotype or subclinical Cushing's syndrome: a 15-year retrospective study. Lancet Diabetes Endocrinol 2014; 2: 396-405.

81. Ermetici F, Malavazos AE, Corbetta S, et al. Adipokine levels and cardiovascular risk in patients with adrenal incidentaloma. Metabolism 2007; 56: 686-92.

82. Babińska A, Pęksa R, Wiśniewski P, Sworczak K. Expression of adiponectin receptors 1 and 2 and leptin receptor in human adrenal tumors. Arch Med Sci 2019; 15: $1254-60$

83. Babińska A, Pęksa R, Wiśniewski P, Świątkowska-Stodulska R, Sworczak K. Diagnostic and prognostic role of SF1, IGF2, Ki67, p53, adiponectin, and leptin receptors in human adrenal cortical tumors. J Surg Oncol 2017; 116: 427-33.

84. Androulakis II, Kaltsas GA, Kollias GE, et al. Patients with apparently nonfunctioning adrenal incidentalomas may be at increased cardiovascular risk due to excessive cortisol secretion, J Clin Endocrinol Metab 2014; 99: 2754-62

85. Fassnacht $M$, Arlt W, Bancos I, et al. Management of adrenal incidentalomas: European Society of Endocrinology Clinical Practice Guideline in collaboration with the European Network for the Study of Adrenal Tumors. Eur J Endocrinol 2016; 175: G1-G34.

86. Babinska A, Siekierska-Hellmann M, Błaut K, et al. Hormonal activity in clinically silent adrenal incidentalomas. Arch Med Sci 2012; 8: 97-103.

87. Dogruk Unal A, Ayturk S, Aldemir D, Bascil Tutuncu N. Serum adiponectin level as a predictor of subclinical Cushing's syndrome in patients with adrenal incidentaloma. Int J Endocrinol 2016; 2016: 8519362.

88. Etxabe J, Vazquez JA. Morbidity and mortality in Cushing's disease: an epidemiological approach. Clin Endocrinol (Oxf) 1994; 40: 479-84.

89. Wagenmakers M, Roerink S, Gil L, et al. Persistent centripetal fat distribution and metabolic abnormalities in patients in long-term remission of Cushing's syndrome. Clin Endocrinol 2015; 82: 180-187.

90. Babinska A, Kaszubowski M, Kmieć P, Sworczak K. Adipokine and cytokine levels in patients with adrenocortical cancer, subclinical Cushing's syndrome and healthy controls. Steroids 2018; 140: 39-44.

91. Barahona MJ, Sucunza N, Resmini E, et al. Persistent body fat mass and inflammatory marker increases after long-term cure of Cushing's syndrome. J Clin Endocrinol Metab 2009; 94: 3365-71.

92. Krsek M, Silha JV, Jezková J, et al. Adipokine levels in Cushing's syndrome; elevated resistin levels in female patients with Cushing's syndrome. Clin Endocrinol 2004; 60: 350-7.

93. Masuzaki H, Ogawa Y, Hosoda K, et al. Glucocorticoid regulation of leptin synthesis and secretion in humans: elevated plasma leptin levels in Cushing's syndrome. J Clin Endocrinol Metab 1997; 82: 2542-7.

94. Gavrila A, Peng CK, Chan JL, Mietus JE, Goldberger AL, Mantzoros CS. Diurnal and ultradian dynamics of serum adiponectin in healthy men: comparison with leptin, circulating soluble leptin receptor, and cortisol patterns. J Clin Endocrinol Metab 2003; 88: 2838-43.

95. Widjaja A, Schürmeyer TH, Von zur Mühlen A, Brabant G. Determinants of serum leptin levels in Cushing's syndrome. J Clin Endocrinol Metab 1998; 83: 600-3.

96. Weise M, Abad V, Considine RV, Nieman L, Rother KI. Leptin secretion in Cushing's syndrome: preservation of diurnal rhythm and absent response to corticotropin-releasing hormone. J Clin Endocrinol Metab 1999; 84: 2075-9.

97. Van Harmelen V, Reynisdottir S, Eriksson P, et al. Leptin secretion from subcutaneous and visceral adipose tissue in women. Diabetes 1998; 47: 913-7.

98. Schwartz MW, Baskin DG, Bukowski TR, et al. Specificity of leptin action on elevated blood glucose levels and hypothalamic neuropeptide $Y$ gene expression in ob/ ob mice. Diabetes 1996; 45: 531-5. 
99. Harman E, Karadeniz M, Biray C, et al. The relation of adiponectin and tumor necrosis factor alpha levels between endothelial nitric oxide synthase, angiotensin-converting enzyme, transforming growth factor beta, and tumor necrosis factor alpha gene polymorphism in adrenal incidentalomas. J Endocrinol Invest 2009; 32: 881-88.

100. Lazúrová I, Spišáková D, Wagnerová H, et al. Clinically silent adrenal adenomas - their relation to the metabolic syndrome and to GNB3 C825T gene polymorphism. Wien Klin Wochenschr 2011; 123: 618-22.

101. Rossi GP, Bernini G, Caliumi C, et al. PAPY Study Investigators. A prospective study of the prevalence of primary aldosteronism in 1,125 hypertensive patients. J Am Coll Cardiol 2006; 48: 2293-300.

102. Born-Frontsberg E, Reincke M, Rump LC, et al. Participants of the German Conn's Registry. Cardiovascular and cerebrovascular comorbidities of hypokalemic and normokalemic primary aldosteronism: results of the German Conn's Registry. J Clin Endocrinol Metab 2009; 94: 1125-30.

103. Fallo F, Veglio F, Bertello C, et al. Prevalence and characteristics of the metabolic syndrome in primary aldosteronism. J Clin Endocrinol Metab 2006; 91: 454-9.

104. Giacchetti G, Ronconi V, Turchi F, et al. Aldosterone as a key mediator of the cardiometabolic syndrome in primary aldosteronism: an observational study. J Hypertens 2007; 25: 177-86.

105. Marzolla V, Armani A, Zennaro MC, et al. The role of the mineralocorticoid receptor in adipocyte biology and fat metabolism. Mol Cell Endocrinol 2012; 350: 281-8.

106. Oda N, Takeda Y, Zhu A, et al. Pathophysiological roles of the adrenal renin-angiotensin system in patients with primary aldosteronism. Hypertens Res 2006; 29: 9-14.

107. Sowers JR, Whaley-Connell A, Epstein M. Narrative review: the emerging clinical implications of the role of aldosterone in the metabolic syndrome and resistant hypertension. Ann Intern Med 2009; 150: 776-83.

108. Letizia C, Petramala L, Tiziana di Gioia CR, et al. Leptin and adiponectin mRNA expression from the adipose tissue surrounding the adrenal neoplasia. J Clin Endocrinol Metab 2015; 100: E101-4.

109. Rossi GP, Sticchi D, Giuliani L, et al. Adiponectin receptor expression in the human adrenal cortex and aldosterone-producing adenomas. Int J Mol Med 2006; 17: 975-80.

110. Fallo F, Della Mea P, Sonino N, et al. Adiponectin and insulin sensitivity in primary aldosteronism. Am J Hypertens 2007; 20: 855-61.

111. Haluzík M, Sindelka G, Widimský J Jr, Prázný M, Zelinka T, Skrha J. Serum leptin levels in patients with primary hyperaldosteronism before and after treatment: relationships to insulin sensitivity. J Hum Hypertens 2002; 16: 41-5.

112. Torpy DJ, Bornstein SR, Taylor W, Tauchnitz R, Gordon RD. Leptin levels are suppressed in primary aldosteronism. Horm Metab Res 1999; 31: 533-6.

113. Ogunwobi OO, Beales IL. Globular adiponectin, activing via adiponectin receptor-1, inhibits leptin-stimulated oesophageal adenocarcinoma cell proliferation. Mol Cell Endocrinol 2008; 285: 43-50.

114. Nakayama S, Miyoshi Y, Ishihara H, Noguchi S. Growthinhibitory effect of adiponectin via adiponectin receptor 1 on human breast cancer cell through inhibition of S-phase entry without inducing apoptosis. Breast Cancer Res Treat 2008; 112: 405-10.
115. Fassnacht M, Dekkers OM, Else T, et al. European Society of Endocrinology Clinical Practice Guidelines on the management of adrenocortical carcinoma in adults, in collaboration with the European Network for the Study of Adrenal Tumors. Eur J Endocrinol 2018; 179: G1-46.

116. Mansmann G, Lau J, Balk E, Rothberg M, Miyachi Y, Bornstein SR. The clinically inapparent adrenal mass: update in diagnosis and management. Endocr Rev 2004; 25: 309-40.

117. Grumbach MM, Biller BM, Braunstein GD, et al. Management of the clinically inapparent adrenal mass ("incidentaloma"). Ann Intern Med 2003; 138: 424-9.

118. Kloos RT, Gross MD, Francis IR, Korobkin M, Shapiro B. Incidentally discovered adrenal masses. Endocr Rev 1995; 16: 460-84.

119. Elenkova A, Matrozova J, Zacharieva S, Kirilov G, Kalinov K. Adiponectin - a possible factor in the pathogenesis of carbohydrate metabolism disturbances in patients with pheochromocytoma. Cytokine 2010; 50: 306-10.

120. Bosanska L, Petrak O, Zelinka T, Mraz M, Widimsky J Jr, Haluzik M. The effect of pheochromocytoma treatment on subclinical inflammation and endocrine function of adipose tissue. Physiol Res 2009; 58: 319-25.

121. Wiesner TD, Blüher M, Windgassen M, Paschke R. Improvement of insulin sensitivity after adrenalectomy in patients with pheochromocytoma. J Clin Endocrinol Metab 2003; 88: 3632-6.

122. Isobe K, Fu L, Tatsuno I, et al. Adiponectin and adiponectin receptors in human pheochromocytoma. J Atheroscler Thromb 2009; 16: 442-7.

123. Böttner A, Eisenhofer G, Torpy DJ, et al. Lack of leptin suppression in response to hypersecretion of catecholamines in pheochromocytoma patients. Metabolism 1999; 48: 543-5. 